\title{
A Institucionalização no Complexo Regional de Segurança Sul-Americano: uma comparação entre quatro períodos históricos
}

\section{The institutionalization in the South American Regional Security Complex: a comparison between four historical periods}

\section{THALES LEONARDO DE CARVALHO ANDRÉA LUIZA FONTES RESENDE DE SOUZA}

\section{INTRODUÇÃO}

Ao longo dos últimos dois séculos, puderam ser observadas diversas mudanças nas dinâmicas regionais relacionadas à segurança na América do Sul. Ao tratar de um Complexo Regional de Segurança (CRS) SulAmericano, Buzan e Waever (2003) notam, por exemplo, alterações entre o período da Guerra Fria e aquele que sucederia seu fim. Essas diferenças não estariam situadas apenas no plano global, mas também nas dinâmicas inter-regionais, regionais e domésticas, pertinentes aos Estados sul-americanos.

No entanto, poucos são os trabalhos que tentam investigar o papel dessas mudanças na institucionalização regional, no que diz respeito à segurança. ${ }^{1}$ É nessa lacuna que este artigo pretende se inserir, visando demonstrar se e como as identidades e interações relacionadas à segurança e defesa entre os países sul-americanos, desde sua independência, se refletiram em alguma institucionalização nesse sentido.

Para tanto, nos propomos a comparar as dinâmicas regionais relacionadas à segurança em quatro períodos diferentes, visando identificar o eventual surgimento de instituições formais em cada um deles. O primeiro vai do momento de independência das colônias sul-americanas ao início do século

Thales Leonardo de Carvalho - Doutorando em Ciência Política pela Universidade Federal de Minas Gerais.

Andréa Luiza Fontes Resende de Souza - Doutoranda em Relações Internacionais pela Pontifícia Universidade Católica de Minas Gerais. 
XX. O segundo período compreende a Segunda Guerra Mundial e a Guerra Fria. O terceiro abrange o período de redemocratização à "Era Neoliberal" e o último período compreende os anos 2000 e a "Virada à Esquerda" sul-americana. Essa separação se deu pensando nas possibilidades de análise das variáveis independentes, tendo em vista que as mesmas apresentam variações em cada um desses períodos, como será demonstrado.

Nesse sentido, elencamos 6 variáveis independentes que podem ter interferido nessa eventual institucionalização. Elas estão divididas em quatro níveis de análise: global, inter-regional, regional; e doméstico. ${ }^{2}$ No nível global, temos como variável as relações entre países sul-americanos e potências globais - mais precisamente a identificação de potências externas à região que influenciaram as dinâmicas regionais sul-americanas -, enquanto no nível inter-regional serão analisadas as relações no âmbito do Atlântico Sul. Já no nível regional, serão estudados possíveis efeitos das relações entre os países sul-americanos nos períodos analisados, incluídas aqui as concepções existentes entre eles sobre integração regional. Outra variável é a percepção de ameaças não-estatais na região, como o crime organizado transnacional e o terrorismo. Por fim, no nível doméstico temos, em primeiro lugar, o tipo de regime dos membros sul-americanos dessas instituições. Para tanto, será utilizada a classificação de Mainwaring e Pérez-Liñán (2013), que os divide em "Democráticos", "Semidemocráticos" e "Autoritários". ${ }^{3}$ A última variável independente consistirá nos itens securitizados em nível doméstico por parte desses países nos diferentes períodos, tais como guerras civis e separatismo.

A variável dependente deste trabalho é a institucionalização regional relacionada à segurança. Para tanto, estipulamos três possibilidades: ausência de institucionalização formal; institucionalização baseada em tratados, regimes e convenções; e formação de organizações internacionais (OIs). Assim, demonstraremos como se apresentavam as variáveis independentes em cada um desses períodos e como as mesmas podem ter influenciado na institucionalização.

Para a construção do argumento pretendido, este trabalho se dividirá em duas partes. Na primeira, procuraremos prover o arcabouço teórico em que será realizada a análise, expondo a teoria dos Complexos Regionais de Segurança, visando entender melhor o papel das dinâmicas regionais de segurança. Apresentaremos também o construtivismo estrutural, objetivando prover um melhor entendimento sobre o papel das identidades e da interação entre os atores para a construção das relações entre eles; e o institucionalismo sociológico, visando entender como essas dinâmicas podem interferir na institucionalização regional relacionada à segurança. Propomos, aqui, que a junção dessas três teorias, a partir de uma análise 
baseada em quatro níveis, poderia trazer-nos explicações mais palatáveis em relação ao objeto de estudo. Em seguida, passaremos à comparação dos diferentes períodos, iniciando pela época de independência e consolidação dos Estados Americanos, passando pela Segunda Guerra Mundial e Guerra Fria, pela redemocratização e a "Era Neoliberal" e, finalmente, chegando à "Virada à Esquerda". Após isso, procederemos à análise do desenho das organizações internacionais citadas.

\section{A CONSTRUÇÃO DE INSTITUIÇÕES EM MEIO ÀS DINÂMICAS REGIONAIS DE SEGURANÇA: OS CRS E O INSTITUCIONALISMO SOCIOLÓGICO}

A teoria dos complexos regionais de segurança (CRS) ganhou força após o final da Guerra Fria. Nesse contexto, Buzan, Waever e Wilde (1998) e Buzan e Waever (2003) destacaram a tendência à regionalização das dinâmicas relacionadas à segurança, tendo em vista que não existiam mais duas superpotências polarizando essas questões. Isso levaria, sobretudo, à uma possibilidade de redução da penetração ou do overlay. ${ }^{4}$

Ganharam força, então, os CRS, entendidos como "um conjunto de unidades cujos principais processos de securitização, dessecuritização, ou ambos, que são tão interligados que seus problemas de segurança não podem ser razoavelmente analisados ou resolvidos separados uns dos outros" (Buzan, Waever e Wilde 1998, 12, tradução nossa). Vale ressaltar que deve haver, também, uma proximidade geográfica entre essas unidades. Nesse sentido, a securitização consiste em um processo em que, através da retórica e da construção intersubjetiva, os atores conferem a um determinado fato/elemento um significado de ameaça, tendo em vista suas vulnerabilidades, de modo que podem ir além das regras existentes (e inclusive quebrá-las) para lidar com esses elementos. Essas ameaças não seriam necessariamente militares, mas poderiam estar relacionadas a qualquer outra área (Buzan, Waever e Wilde 1998; Guzzini 2003).

Buzan e Waever (2003) e Stewart-Ingersoll e Frazier (2012) propõem divisões dos CRS ao redor do mundo. Apesar de diferenças em relação a outras partes do globo, os autores veem dois complexos nas Américas: um na América do Norte (embora incluam os países da América Central e do Caribe) e outro na América do Sul. Buzan e Waever (2003) destacam ainda a existência dois subcomplexos em meio ao CRS sul-americano: o Norte Andino, que envolve a Colômbia, Equador, Guiana, Peru e Venezuela; e o Cone Sul, que inclui a Argentina, Bolívia, Brasil, Chile, Paraguai e Uruguai. Portanto, em meio às relações construídas entre os atores, o poder, principalmente material, viria a definir a polaridade existente dentro dos CRS. 
Esses complexos poderiam ter um ou mais polos (sendo eles Estados ou instituições), que poderiam ser potências regionais ou externas que pratiquem overlay ou não terem polos (Buzan e Waever 2003; Stewart-Ingersoll e Frazier 2012).

Outro elemento que deve ser levado em conta para o entendimento dos mesmos é a construção social das relações entre atores. É nesse ponto que o Construtivismo Estrutural, cujo principal autor é Alexander Wendt (1992; 1999), colabora na construção de nosso framework teórico, ao prover-nos elementos para o entendimento dessas relações. Assim como a securitização, a anarquia do Sistema Internacional (e as relações nos CRS) também são construídas através das interações entre os membros desses sistemas (Wendt 1992). Nesse sentido, as ações dos atores seriam norteadas, em parte, pela razão, mas também por suas identidades, crenças e valores. Nesse sentido, as interações entre eles poderiam levar a três tipos de percepções mútuas:

- A rivalidade entre os atores que se percebem como inimigos, levando a relações mais conflituosas. Wendt (1999) vê essa relação como hobbesiana, enquanto Buzan e Waever (2003) classificam os CRS desse tipo como "formações conflituosas".

- Já o segundo não vê os outros atores necessariamente como aliados, mas também não os vê como inimigos. As ameaças existem, mas os atores reconhecem que podem coexistir e, eventualmente, cooperar. Esse tipo de relação é visto como lockeano por Wendt, enquanto Buzan e Waever (2003) denominam como "regimes de segurança" os CRS em que esse tipo de relação existe.

- Por fim, existem as "comunidades de segurança”, como denominadas por Buzan e Waever (2003), em que predominam relações vistas como kantianas por Wendt (1999). Nesses casos, os atores não percebem ameaças entre si e tendem a se associar e cooperar.

Logo, as interações entre os atores, baseadas em suas identidades, constroem a estrutura do sistema social em que os mesmos estão inseridos; ao longo do tempo, essa mesma estrutura seria capaz de interferir nas identidades dos atores, em um ciclo contínuo. Essas interações geram também as instituições, vistas por Wendt (1992, p. 399, tradução nossa) como "conjuntos relativamente estáveis ou estrutura de identidades e interesses”. Visão parecida nos é apresentada por Hall e Taylor (2003), ao tratar sobre o institucionalismo sociológico. Assim, as instituições tornam-se um reflexo das identidades e culturas de seus membros. Essas instituições são formais ou informais, e não teriam apenas um caráter cooperativo, poden- 
do ser também conflituais - como, por exemplo, a busca pela sobrevivência (autoajuda) em um sistema hobbesiano (Wendt 1992; Johnston 2001; Bernstein 2002).

As instituições, uma vez constituídas pelas interações entre os atores, teriam também a capacidade de afetar os comportamentos e, até mesmo, as identidades dos mesmos - assim como a dualidade da estrutura. Para sobreviver, no entanto, elas deveriam conseguir acompanhar as mudanças nas identidades de seus membros. Sua própria legitimidade estaria ligada a isso, visto que, quanto mais conseguissem refletir as culturas e identidades de seus atores, mais dotada de legitimidade elas seriam (Wendt 1992; Johnston 2001; Bernstein 2002).

Sendo assim, as próprias instituições regionais relacionadas à segurança seriam frutos das identidades dos atores em meio a um CRS. Essas identidades tendem a se alterar ao longo do tempo, em função de diversos fatores, seja no nível global, inter-regional, regional ou doméstico. É com base nesse framework analítico que pretendemos mostrar como as identidades regionais relacionadas à segurança no CRS sul-americano se refletiram em diferentes arranjos institucionais ao longo de diversos períodos.

\section{DINÂMICAS DE SEGURANÇA NA AMÉRICA DO SUL}

Partiremos agora à exposição sobre as dinâmicas de segurança na América Latina em diferentes períodos. Neste tópico serão explorados os possíveis impactos das seis variáveis independentes elencadas, em quatro diferentes níveis de análise, sobre a eventual institucionalização regional relacionada à segurança. Os períodos expostos serão divididos em: da independência dos países sul-americanos até os anos 1930; Segunda Guerra Mundial e Guerra Fria; a redemocratização e a "Era Neoliberal"; e a "Virada à esquerda". Como poderá ser percebido, essa separação deu-se em função de alterações nas variáveis explicativas em cada um desses períodos. A partir disso, procuraremos demonstrar o papel dos fatores elencados no surgimento das referidas instituições.

\section{Da independência ao início do século XX: a ausência de institucionalização em âmbito regional relacionada à segurança}

Os países sul-americanos foram tornando-se independentes, em sua maioria, ao longo do século XIX e, neste período, as grandes potências europeias disputavam a influência sobre a região. No entanto, em 1823, o então presidente estadunidense, James Monroe, idealizou que os Estados de todas as Américas não deveriam mais estar suscetíveis ao imperialis- 
mo europeu. Na prática, isso serviu mais como um imperativo moral, tendo em vista que os EUA não possuíam poder suficiente (principalmente militar, marítimo) para confrontar as nações europeias, principalmente o Reino Unido, que tinha a maior influência sobre a região à época. Logo os Estados Unidos foram ganhando força na região e, cada vez mais, reduzindo a influência europeia na região. A América seria um continente para os americanos; mais especificamente para os estadunidenses (Buzan e Waever 2003; Kacowicz 1998).

Esse entendimento é importante para explicar a influência e a dominação cada vez maior dos EUA sobre a América Latina como um todo. Essa ideia ganhou força com a doutrina do big stick, de Theodore Roosevelt, entre 1900 e 1915. De forma resumida, essa concepção se refere ao fato de que os EUA deveriam intervir nas dinâmicas de segurança latino-americanas, reforçando sua presença e reduzindo a de outras potências, utilizando, inclusive, da força militar. Nesse contexto, as intervenções armadas dos estadunidenses na região tornaram-se cada vez mais comuns; os objetivos, no entanto, não eram altruístas, mas sim ligados aos interesses econômicos e geopolíticos dos EUA (Buzan e Waever 2003; Abdul-hak 2013). O intervencionismo direto estadunidense em assuntos dos países latino-americanos, com a política do big stick, duraria até os anos 1930, quando Franklin Roosevelt optou por uma dominação através da ajuda/cooperação econômica, em detrimento do uso da força física (Smith 1996).

Essa relação entre as grandes potências se refletiu, também, no Atlântico Sul. Durante parte do século XIX, o Reino Unido possuía forte presença na região, com seus territórios ultramarinos sul-atlânticos. Com a construção do Canal de Suez, em 1869, essa importância viria a diminuir muito, tendo em vista o estabelecimento de uma nova rota comercial, alternativa ao Atlântico. Isso levou a um afastamento das grandes potências das dinâmicas da região (que já era periférica em detrimento a outras rotas marítimas), junto a um certo desinteresse, também, dos países sul-americanos pela área; à época, a maior parte dos territórios africanos ainda eram colônias. No início do século XX, com o big stick, os EUA aumentaram sua presença na região, enquanto os países sul-americanos como o Brasil e a Argentina careciam de uma política naval para aumentar o controle da região sul-atlântica (Penha 2011; Silva 2014).

Enquanto nos níveis global e inter-regional o contexto era de crescente penetração dos EUA sobre as dinâmicas que envolviam os países latino-americanos, no âmbito regional o século XIX foi marcado por diversas controvérsias e conflitos interestatais na busca por expansão e consolidação dos territórios dos países recém-formados (Kacowicz 1998); Buzan e Waever (2003) percebem pelo menos 3 conflitos importantes nesse perío- 
do, como as guerras do Paraguai e do Pacífico. Isso ocorreu pois as fronteiras desses países eram mal definidas durante o período colonial e assim se mantiveram após a obtenção da independência desses atores. Junto a isso, no âmbito doméstico, os novos Estados conviveram com instabilidade e guerra civis durante os processos de statebuilding (Buzan e Waever, 2003).

Apesar do caráter aparentemente pacífico que a diplomacia conferia à América Latina no início do século XX, ainda houve guerras entre países da região, como a Guerra do Chaco, entre Bolívia e Paraguai, nos anos 1930, por motivos territoriais. Nesse sentido, Kacowicz (2003) vê um contexto de paz negativa ${ }^{5}$ na região. $O$ contex to conflituoso era marcado ainda pelas intervenções estadunidenses no subcontinente, sob a doutrina do big stick. Para Buzan e Waever (2003), a região consistia em uma formação conflituosa durante a maior parte desse período.

Ainda no início do século XX, após o estabelecimento e a consolidação, em alguma medida, desses novos Estados, o que se começou a ver foi uma integração das economias locais às mundiais e o triunfo de ideias liberais, apoiadas ora pelo Reino Unido, ora pelos Estados Unidos. As oligarquias ganharam cada vez mais força e, à medida que os impérios foram se tornando repúblicas, foram mantendo-se como elite política nos países da região - segundo Mainwaring e Pérez-Liñán (2013), entre 1900 e 1939, apenas a Argentina e o Uruguai tiveram períodos democráticos, enquanto os demais países da região viviam sob regimes autoritários ou semidemocráticos. As relações entre os países foram se construindo e consolidando, junto à emergência de um balanço de poder entre Brasil e Argentina, mas levando em conta também Chile e Peru (Kacowicz 1998; Buzan e Waever 2003). Por fim, a Grande Depressão de 1929 levou também a crises econômicas nos países da região. Somadas à insatisfação com a dominação das oligarquias, esses fatores levaram a golpes militares em alguns países latino-americanos e à chegada ao poder de alguns líderes populistas, como Getúlio Vargas, no Brasil (Kacowicz 1998).

Logo, vê-se que, em âmbito regional e doméstico, esse período foi marcado pela construção dos Estados - e, segundo Mainwaring e PérezLiñán (2013), com a tendência a regimes autoritários ou pouco democráticos - e das relações entre os atores regionais, com forte penetração estadunidense, tanto nas dinâmicas de segurança sul-americanas quanto naquelas do Atlântico Sul. Essa penetração, no entanto, não buscava a pacificação da região, mas focava na expansão da influência estadunidense no subcontinente a qualquer custo. Somando isso aos processos de statebuilding e às fronteiras mal definidas, o que se pode inferir é que, durante o século XIX, a América do Sul poderia ser vista até mesmo como uma "formação conflituosa", caracterizada por relações hobbesianas 
entre seus países. Nesse processo, para além dos conflitos interestatais, a securitização relacionada a grupos não-estatais a nível doméstico passava pelos atores (guerrilhas) envolvidos nas guerras civis e, em âmbito regional, pelo eventual spillover desses conflitos. Em meio a esse ambiente, não houve iniciativas institucionais formais relacionadas à segurança na região. O fraco interesse dos EUA de se engajarem no desenvolvimento da região e/ou em iniciativas multilaterais também colaborou para ausência dessa institucionalização.

\section{Segunda Guerra Mundial e Guerra Fria: sob a esfera de influência dos EUA}

Com o início da Segunda Guerra Mundial, os EUA intensificaram suas iniciativas na região, visando manter sua esfera de influência e afastar, principalmente, a Alemanha nazista (JID 2018). Já desde 1933, com a chegada de Franklin Delano Roosevelt ao poder, o país havia substituído a doutrina do big stick pela Política de Boa Vizinhança. Assim, ao invés da força militar, os estadunidenses passaram a utilizar da diplomacia, do diálogo e da cooperação na construção das relações com os países latinos e sul-americanos (Abdul-Hak 2013).

Nesse contexto, tendo em vista a ameaça nazista e o ambiente de cooperação que vinha sendo construído com a Política de Boa Vizinhança, em 1942 foi criada, por iniciativa estadunidense, a primeira instituição das Américas com o objetivo de lidar com temas militares: a Junta Interamericana de Defesa (JID). Foi-se tentando desenvolver cada vez mais uma concepção de uma América unida (sob a liderança dos EUA) e, ao longo do tempo, surgiu a ideia de que um ataque a um país da região representaria um ataque a todos os Estados americanos, que culminaria no Tratado Interamericano de Assistência Recíproca (TIAR), assinado em 1947. Já em 1948, foi celebrado o Pacto de Bogotá, que buscava mecanismos de resolução pacífica de conflitos na região da América do Sul. No mesmo ano, foi criada a Organização dos Estados Americanos (OEA), que incluiria, no momento, todos os países da região. Em 1962, foi criado o Colégio Interamericano de Defesa, visando treinamentos e doutrinamento conjuntos aos oficiais das forças armadas da região; que, na prática, viriam a refletir os valores estadunidenses, servindo como mais um instrumento de difusão de tais valores. Essas instituições viriam a formar o Sistema Militar Interamericano - SMI (Abdul-hak 2013; Martins Filho 1999; Fuccille 2014). Ainda em relação aos regimes de segurança pan-americanos, em 1967 seria assinado o Tratado de Tlatelolco, firmando o compromisso entre todos os países da América Latina e do Caribe de fazer da região uma zona livre de armas nucleares (Abdul-hak 2013). 
Nesse período, o único mecanismo que disponibilizaria um espaço para o debate e coordenação de políticas de segurança e defesa na região era a JID. Até mesmo o TIAR que, teoricamente, buscava esse objetivo, não implementou estruturas que possibilitaram essa coordenação, ficando esta a cargo de acordos bilaterais, normalmente envolvendo os EUA (Penha 2011).

É importante notar a influência dos EUA sobre o SMI. No caso da JID, por exemplo, até o final da década de 1990 o presidente da instituição deveria ser, necessariamente, um militar estadunidense (JID 2018). Além disso, autores como Martins Filho (1999) e Abdul-Hak (2013) percebem a forte penetração de ideais estadunidenses nessas instituições, algo evidenciado, por exemplo, pela adoção da securitização da ameaça comunista durante a Guerra Fria, pauta defendida pelos Estados Unidos. Além disso, Meek (1975) percebeu que os EUA conseguiam a aprovação das resoluções que lhes eram mais importantes à época, obtendo sempre um número de apoiadores referente, no mínimo, à maioria qualificada dos votos na instituição.

Além do uso de instituições regionais para difundir sua política anticomunista, os Estados Unidos viriam ainda a intervir na esfera doméstica dos países da região (Teixeira 2012; Martins Filho 1999). Quando governos que aparentavam tendências esquerdistas chegaram ao poder, os estadunidenses apoiaram golpes militares nesses países. No caso brasileiro, por exemplo, o então presidente João Goulart foi derrubado em 1964, dando início a duas décadas de governos militares. Assim, embora tenham sido vistos alguns regimes democráticos na região durante parte dos anos 1950 e 1960, golpes militares se sucederam nos países que tinham algum nível de mobilização da esquerda, levando a ditaduras que visavam a deter a expansão do comunismo na região, no contexto da Operação Condor, desempenhada pelos EUA. Mainwaring e Pérez-Liñán (2013) destacam que, no período da Guerra Fria, a maior parte dos países latino e sul-americanos contaram com governos autoritários. Nesse sentido, é possível dizer que houve grande ligação entre os níveis global, regional e doméstico de análise. A penetração estadunidense chegou aos demais níveis, com a influência no Atlântico Sul, a formação de instituições regionais (SMI) e o apoio à chegada de ditaduras ao poder para deter o avanço comunista na região. O discurso dos EUA de securitização do comunismo acabou, também, chegando aos níveis regional e doméstico, levando à securitização do comunismo e seus apoiadores, dentre eles as guerrilhas comunistas.

Em nível regional, as relações continuaram sendo caracterizadas por uma "paz negativa”, com a contínua existência de controvérsias entre os atores. As ditaduras militares à época não fizeram grandes esforços para construir confiança na região. No entanto, a ação estadunidense e algum nível de confiança construída entre essas ditaduras levou a uma redução 
no número de conflitos intrarregionais. De forma geral, a relação entre os países sul-americanos progredia, chegando a uma cultura lockeana nessas interações (Kacowicz 1998; Buzan e Waever 2003).

No nível inter-regional, durante a Segunda Guerra, o Atlântico Sul se tornou alvo de $u$-boats alemães que naufragaram navios mercantes que passavam pela região. Logo, os EUA criaram a Quarta Esquadra do Atlântico Sul buscando exercer maior presença na região. Após a guerra, no entanto, a importância geoestratégica do Atlântico Sul diminuiu, levando também a uma redução do interesse dos EUA. Isso abriu margem para que Estados sul-atlânticos como a Argentina, África do Sul e Brasil buscassem o protagonismo na região - sem contestar, no entanto, a hegemonia estadunidense. Com a expansão da influência da URSS no continente africano na década de 1960, a região sul-atlântica voltou a fazer parte dos cálculos estratégicos dos Estados Unidos (Penna Filho 2003; Penha 2011; Souza 2017).

Além das iniciativas pan-americanas lideradas pelos EUA, uma incipiente integração regional parecia surgir. Houve tentativas de criação de instituições que visavam à integração comercial como: a Associação Latino-Americana de Livre Comércio (ALALC), surgida na década de 1960, e que viria a se expandir e se tornar a Associação Latino-Americana de Desenvolvimento e Intercâmbio (ALADI) em 1980. A efetividade dessas iniciativas é discutível quando considerado o caráter protecionista e pouco industrializado dos países.

Enquanto isso, no Atlântico Sul, entre as décadas de 1950 e 1960, os países sul-americanos começaram a tentar promover iniciativas para além das interamericanas, iniciando uma mobilização para a criação de uma instituição de segurança coletiva. Em 1956 houve uma tentativa frustrada de criação de um pacto militar entre Argentina, Brasil e Uruguai. Já em 1969 foi proposta pela África do Sul a criação da Organização do Tratado do Atlântico Sul (OTAS). Destaca-se que, mesmo sendo uma iniciativa de países do sul global, a OTAS teve apoio dos Estados Unidos. Os EUA acreditavam que, se a iniciativa partisse de um Estado-protagonista da região, haveria maiores chances de aceite pelos Estados sul-atlânticos. Ademais, a proposta era estabelecer uma instituição nos moldes da Organização do Tratado do Atlântico Norte (OTAN), ou seja, uma aliança militar. A intenção real era criar uma espécie de contenção que barrasse a influência soviética sobre a região sul-atlântica; percebe-se assim, mais uma vez, a influência exercida pelos EUA nas relações sul-sul.

A iniciativa da OTAS, no entanto, não prosperou. Entre outros motivos está o fato de tentarem incluir um número muito grande de Estados, inclusive externos à região como a Austrália e a Nova Zelândia. A discrepante 
participação de países extra regionais e o desinteresse do governo brasileiro em firmar o pacto levou a um desinteresse coletivo em continuar as negociações. Nem mesmo os Estados Unidos, que estavam por trás da iniciativa, continuaram a estimular as negociações (Penna Filho 2003; Penha 2011).

A proposta da OTAS surgiu novamente em maio 1981, mas com a Guerra das Malvinas, em 1982, as relações entre os potenciais membros da OTAS se estremeceram. Enquanto a Argentina buscava sua consolidação enquanto potência militar na América do Sul, tanto a África do Sul quanto os Estados Unidos apoiaram o Reino Unido no conflito. No mesmo período, as relações entre Brasil e África do Sul esfriaram, em função do programa nuclear sul-africano e do regime do apartheid. O Brasil viria a se aproximar da Nigéria, que fazia coro a um Atlântico Sul desmilitarizado. Nesse sentido, a iniciativa da OTAS foi, de uma vez por todas, esquecida (Penha 2011).

Conclui-se que o período compreendido entre a Segunda Guerra e a Guerra Fria foi caracterizado pela ampliação da penetração estadunidense no CRS sul-americano, desta vez com a Operação Condor e a Política de Boa Vizinhança, além da forte influência naquelas relacionadas ao Atlântico Sul. Com essa penetração e a emergência de uma cultura lockeana nas relações entre os países sul-americanos, com níveis decrescentes de rivalidade entre si, vê-se o surgimento do Sistema Militar Interamericano, ancorado no papel estadunidense de "protetor" da região. Houve, ainda, a tentativa de criação da OTAS, além do surgimento de alguma institucionalização relacionada ao comércio regional. Essa institucionalização teria sido possibilitada pela mudança de um ambiente hobbesiano para outro lockeano na região, permitindo o diálogo e o desenvolvimento de cooperação entre os países sul-americanos - junto à atuação dos Estados Unidos, como paymaster desse processo.

\section{Da redemocratização à "Era Neoliberal"}

Com o fim da Guerra Fria, viu-se também um declínio no interesse dos Estados Unidos em influenciar diversas regiões do mundo; inclusive a América do Sul. A ordem liberal já havia vencido (Fukuyama 1992). Nesse contexto, os EUA não precisariam mais despender muitos recursos para manter sua influência na região. ${ }^{6}$ A maior interferência estadunidense em assuntos de segurança, nesse sentido, estaria relacionada à securitização do narcotráfico, com o discurso de "Guerra às Drogas". Essa interferência se daria mais fortemente na região andina, com foco na Colômbia (Buzan e Waever 2003). Assim, durante esse período, os países sul-americanos continuariam mais próximos aos EUA, mesmo que a potência tenha se empe- 
nhado menos nas relações com esses atores. A OEA e o SMI continuariam a ser as únicas instituições formais a lidarem com os temas de segurança e defesa na região.

Ainda nesse contexto, as ditaduras militares na região já não se faziam necessárias, abrindo espaço para a promoção de democracias. Assim, os países sul-americanos que haviam passado por esses governos autoritários foram se redemocratizando; Mainwaring e Pérez-Liñán (2013) destacam que, nos anos 1990, a grande maioria dos Estados da região possuíam regimes democráticos.

Foram surgindo novas oportunidades de interações entre os países, tanto em âmbito regional como no Atlântico-Sul. Essas oportunidades levaram à possibilidade de formação de novas instituições. O Brasil, em meio à sua transição para a democracia, buscou consolidar seu papel como regional player. Por sua vez, a aproximação entre brasileiros e africanos fazia parte da política externa brasileira desde 1975, visando a expandir as relações no âmbito sul-sul (Penha 2011; Teixeira 2012). Em meio a esse processo, o Brasil lançou uma iniciativa para a criação de uma instituição que fomentasse a cooperação em segurança entre os dois lados do Atlântico Sul. Assim, em 1986, foi aprovada na Assembleia Geral das Nações Unidas a criação da Zona de Paz e Cooperação do Atlântico Sul (ZOPACAS). Além de promover a cooperação, a estabilidade e a paz, a Zona tem como princípios a desmilitarização e a não-intervenção de potências estrangeiras. Assim, a ZOPACAS uniu o Brasil, a Argentina e o Uruguai em um arranjo de segurança coletiva juntamente com 21 países africanos (Penha 2011, 2012; Penna Filho 2003; Silva 2014).

A ZOPACAS iniciou suas atividades em 1990, porém, as iniciativas neoliberais propostas pelos governos sul-americanos durante a década de 1990, principalmente o Brasil, causaram um afastamento das relações com a África, causando uma estagnação da ZOPACAS. Logo, o papel do Brasil como regional player das relações sul-atlânticas foi fundamental tanto para o crescimento quanto para o declínio das relações no âmbito da instituição (Penha 2011; 2012).

No âmbito regional, as relações entre os países sul-americanos se intensificaram. Assim, em meio à prevalência dos ideais liberais no mundo no pós-Guerra Fria, ganhou força a ideia de consolidação da interdependência (principalmente econômica) entre os países da região. Surgia assim uma nova forma de integração, que ficou conhecida como "regionalismo aberto", baseada na "interdependência nascida de acordos especiais de caráter preferencial e conduzida basicamente por sinais do mercado resultantes da liberalização comercial em geral” (CEPAL 1994, tradução nossa). A integração regional se daria, basicamente, através do comércio entre os países 
sul-americanos, bem como da integração comercial dos mesmos ao resto do mundo, em bloco.

Neste contexto, tentou-se criar a Área de Livre Comércio das Américas (ALCA), que não lograria sucesso. A falta de acordo entre as partes e o fraco interesse estadunidense na iniciativa estariam entre as causas desse insucesso. Os EUA, assim, acabariam optando por acordos bilaterais com os países sul-americanos. (Teixeira 2012). O Pacto Andino viria a se tornar a Comunidade Andina de Nações (CAN), visando estreitar as relações comerciais entre seus membros, na parte norte da América do Sul. Enquanto isso, na parte sul, o Mercado Comum do Sul (Mercosul) foi criado, objetivando o estreitamento das relações comerciais entre Argentina, Brasil, Paraguai e Uruguai. Em meio ao regionalismo aberto, ganhou força também a ideia de que a integração comercial levaria a uma região ainda mais pacífica, tendo em vista as interações cada vez maiores e a interdependência crescente entre os países da região e a possibilidade de spillover para outras áreas. Ainda assim, a cooperação militar entre os países ainda era majoritariamente bilateral, carecendo de uma instituição regional de defesa que gerasse integração e coordenação multilateral de políticas de defesa (Silva 2014).

Embora essa integração comercial tivesse o potencial de reduzir a probabilidade de conflitos interestatais, ganharam destaque nesse contex to as ameaças não-estatais. Embora as guerrilhas relacionadas ao socialismo tenham perdido espaço, o crime organizado passou a ser uma das principais fontes de insegurança na região, passando a serem securitizados tanto no nível regional quanto doméstico. Para além de delitos como o tráfico de armas e de seres humanos, o narcotráfico receberia cada vez mais destaque, com a mencionada influência do discurso de "Guerra às drogas" dos Estados Unidos. Além disso, pautas relacionadas aos indígenas e raciais foram ganhando cada vez mais força na região. O desenvolvimento social também passou a ganhar espaço, mas não tanto quanto receberia no período seguinte. (Buzan e Waever 2003). É interessante notar como os problemas domésticos possuem ligações próximas com a securitização regional na América do Sul, em função da grande possibilidade de spillover.

Assim, durante esse período, o que se viu foi a manutenção de uma cultura lockeana nas relações entre os países da região, mas com um eventual incremento na confiança entre eles, através da crescente interdependência econômica. Junto a isso, reduziu-se muito a penetração dos EUA no CRS sul-americano. Nesse período, o que se viu foi a tentativa de criação da ZOPACAS, que acabou por não alcançar níveis destacáveis de institucionalização, tendo em vista a falta de interesse de seus membros e, principalmente, do Brasil. Assim, as instituições regionais capazes de lidar com 
temas de segurança e defesa ainda estavam relacionadas ao SMI, com a interferência estadunidense. A institucionalização formal sul-americana se deu, na verdade, através da formação (ou ao menos a tentativa) de organizações ligadas ao comércio, como o Mercosul e a CAN que, como se pensava à época, deveriam levar a um spillover para a segurança e a defesa na região.

\section{Os anos 2000 e a "Virada à Esquerda" na região: o surgimento da UNASUL e do CDS}

Na década de 2000, percebe-se um declínio ainda maior do interesse dos EUA em relação à América do Sul. Com os atentados de 11 de setembro de 2001, os países latino-americanos não possuiriam grande importância no contexto da "Guerra ao Terror", principal agenda do discurso securitizador estadunidense nos anos 2000. Essa securitização chegaria apenas à Colômbia, atribuindo a organizações ligadas ao narcotráfico, como as FARC, o significado de terroristas, dando continuidade à ajuda dos EUA ao país. (Buzan e Waever 2003). Enquanto isso, a China conseguiu cada vez mais influência na região, baseada, principalmente, no poder econômico e comercial. Os chineses estreitaram as relações com os países latino-americanos, tornando-se um player cada vez mais importante; embora não tenham apresentado ainda influência direta nas dinâmicas relacionadas à segurança. É notória também a aproximação da Rússia em relação a alguns países da região (Stewart-Ingersoll e Frazier; 2012).

Percebe-se também que o Atlântico Sul voltou a ganhar relevância nas políticas das grandes potências. Além da China se tornar o principal parceiro comercial na América do Sul e na África, muito em razão dos recursos naturais africanos, os EUA criaram o Comando da África (AFRICOM) em 2007, e reativaram a Quarta Esquadra em 2008. ${ }^{7}$ As relações entre os países dos dois lados do Atlântico do Sul também se intensificaram com a maior ênfase dada pelos governos da região à cooperação Sul-Sul. Neste contexto, a ZOPACAS seria revitalizada por dois planos, o Plano de Ação de Luanda de 2007 e o de Montevidéu de 2013. Em suma, as iniciativas pretendiam aumentar o escopo da cooperação na zona para áreas como meio ambiente, cooperação econômica, ações anti-tráfico de drogas e armas, peacebuilding, entre outras, incentivando cada vez mais as ações conjuntas. A efetividade dos planos, no entanto, é discutível, de modo que se pode dizer que a Zona nunca alcançou níveis destacáveis de institucionalização (Penha 2011; 2012; Amorim 2013; Caldas 2013).

Nesse período, as principais mudanças ocorreram nos níveis doméstico e regional. Nos anos 2000, como visto por Mainwaring e Pérez-Liñán 
(2013), a maioria dos países sul-americanos tiveram regimes democráticos por, pelo menos, dois anos. A democracia, aliada a fatores como a insatisfação com a tentativa de implementação de modelos neoliberais e a influência dos EUA na região, possibilitaria uma "Virada à esquerda" na região. Além de mudanças nas políticas domésticas e externas dos países sul-americanos, houve uma reconfiguração na percepção em torno da integração regional. $\mathrm{Na}$ visão desses governos de esquerda e centro-esquerda, a integração não deveria se restringir a aspectos comerciais e econômicos, mas deveria se expandir para todas as áreas, sejam as políticas sociais, infraestruturais, ambientais, de segurança e de defesa, entre outras. Além disso, passou-se a adotar uma retórica que visava a cada vez mais contestar a hegemonia e a influência dos Estados Unidos na região (Veiga e Rios 2007; Gratius 2012; Riggirozzi 2012).

Cabe ressaltar que, nesse contexto, houve pelo menos dois tipos de esquerda na região: uma mais institucionalizada, moderada e menos crítica à sociedade capitalista, mais adaptada ao "jogo democrático", representada pelo Partido dos Trabalhadores (Brasil), Partido Socialista (Chile) e Frente Ampla (Uruguai); a outra, mais radical e menos institucionalizada, crítica do sistema capitalista e da influência dos EUA, representada pelo Movimento V República/Partido Socialista Unido da Venezuela (Venezuela), Aliança PAIS (Equador) e Movimento ao Socialismo (Bolívia) (Silva 2011; Levitsky e Roberts 2011). O segundo tipo de esquerda será tratado aqui sob a alcunha de "bolivarianismo".

Com isso, o que se viu foram mudanças institucionais, bem como a criação de outras novas instituições. O Mercosul, por exemplo, outrora concebido como um bloco comercial, recebeu estruturas relacionadas às políticas sociais e redução de assimetrias. Até mesmo o SMI passou por mudanças, como a chegada de militares de outros países (que não os EUA) à presidência da JID e a inclusão desta ao organograma da OEA (JID 2018). Foram fundadas, também, a Comunidade de Estados Latino-Americanos e Caribenhos (CELAC) - que, nas palavras do presidente equatoriano, Rafael Correa, consistiria em um "Consenso sem Washington" - e a Alternativa Bolivariana para os Povos de Nossa América (ALBA). Não será delongada a descrição dessas instituições por não irem ao encontro do propósito deste trabalho. Surgiu também, nesse contexto, a União de Nações SulAmericanas.

No âmbito da UNASUL, no mesmo ano de sua criação (2008), um cenário de crise quase levou a um conflito bélico na região. Na tentativa de atingir um dos líderes das Forças Armadas Revolucionárias Colombianas (FARC), o governo colombiano efetuou um ataque aéreo em uma região de mata, no sudoeste do país. O ataque, no entanto, acabou por ocorrer em 
território equatoriano, na região de Angostura, sem qualquer autorização do governo local. Essa violação à soberania do Equador levou a um cenário de crise, agravado ainda mais por fatores ideológicos: a Colômbia, apoiada pelos Estados Unidos, havia violado um direito de um país "bolivariano", fortemente crítico aos EUA e apoiado pela Venezuela, vista por diversos atores com apoiadora das FARC (Abdul-hak 2013; Fuccille 2014).

Nesse contexto, não havia órgãos regionais (sul-americanos) capazes de atuar nessa crise. A OEA foi acionada para atuar nesse sentido, mas sem grande legitimidade, tendo em vista a influência estadunidense na organização. O que se percebeu foi a necessidade de um órgão sul-americano que fosse capaz de lidar com um problema entre países sul-americanos. Mais do que isso, para o governo brasileiro, a existência de uma estrutura que permitisse a cooperação de políticas de segurança e defesa na região, bem como o intercâmbio de informações, poderia ter evitado a emergência dessa crise. Cabe mencionar que já havia ocorrido encontros de Ministros da Defesa sul-americanos desde 2006, demonstrando possibilidades em torno desses intercâmbios (Abdul-Hak 2013).

Neste contexto, Fuccille e Rezende (2014) percebem mudanças nas dinâmicas regionais relacionadas à segurança, caracterizadas pelos seguintes pontos:

(1) a possibilidade de transbordamento das novas ameaças a outros países, como o narcotráfico colombiano para o Brasil e a contenda envolvendo Colômbia, Equador e Venezuela pela morte do número dois das FARC, Raúl Reyes; (2) os conflitos sub-regionais, como os contenciosos envolvendo Peru e Equador, Bolívia e Chile, entre outros; (3) os movimentos autóctones difundindo um sentimento separatista, como ilustram Bolívia e Paraguai; [...] (5) evitar uma corrida armamentista na região, com a adoção crescente de medidas de confiança mútua; (6) solidificar o Atlântico Sul como uma área de paz, livre de armas nucleares [...]; (7) impedir a materialização de uma política estratégica de segurança hemisférica definida a partir dos Estados Unidos para o subcontinente (Fuccille e Rezende 2014, 88).

Os autores partem de uma ótica brasileira, tendo em vista que o país buscava cada vez mais o papel de líder regional, objetivando frear o bolivarianismo na região. Assim, depois de muitas negociações e resistência, principalmente da Colômbia, foi criado, sob a liderança do brasileira, o Conselho de Defesa Sul-Americano, a primeira instituição sul-americana a lidar com assuntos de segurança e defesa sem a atuação direta dos EUA. Foi criado, ainda no âmbito da instituição, um conselho para lidar com o problema das drogas e outro para lidar com os crimes internacionais; sua 
eficácia, no entanto, tem sido discutida, sendo vista como praticamente nula por alguns autores, ao contrário do CDS (Carvalho 2018; Fuccille 2018).

O que se vê neste contex to é o declínio da influência dos EUA na região, que passou também a ser contestada pelos países sul-americanos, enquanto a China ganhou cada vez mais espaço, assim como a Rússia, em alguma medida. Junto a isso, a ênfase dos governos de esquerda nas relações com países do sul global levou à aproximação no âmbito do Atlântico Sul, assim como à tentativa de revitalização da ZOPACAS. Em nível regional, a securitização no CRS sul-americano passou a focar, principalmente, em ameaças não-estatais, como o narcotráfico. O desenvolvimento social também ganhou cada vez mais espaço, sendo aderido aos discursos em fóruns globais relacionados à segurança, como visto por Carvalho (2018). Nas relações interestatais, o que se viu foi a manutenção de uma cultura lockeana, com níveis de confiança ainda maiores do que os anteriores. Por fim, em meio às democracias e governos de esquerda democraticamente eleitos na região, pareceu-se tentar cada vez mais a criação de uma identidade sul-americana comum, chegando até mesmo a abrir a possibilidade de evolução de uma cultura lockeana para uma kantiana no longo prazo. Nesse contexto, foi criada a primeira instituição sul-americana capaz de lidar com temas de segurança e defesa: o CDS, no âmbito da UNASUL. Vale dizer que esse processo pode estar sendo interrompido com a chegada de governos com tendências à centro-direita na região, principalmente com a suspensão da participação dos mesmos na UNASUL (Paraguassu 2018); não discutiremos aqui, no entanto, as causas dessa saída. Por fim, o quadro abaixo sumariza a presença das variáveis em cada um dos contextos analisados, bem como a institucionalização nesses períodos. 


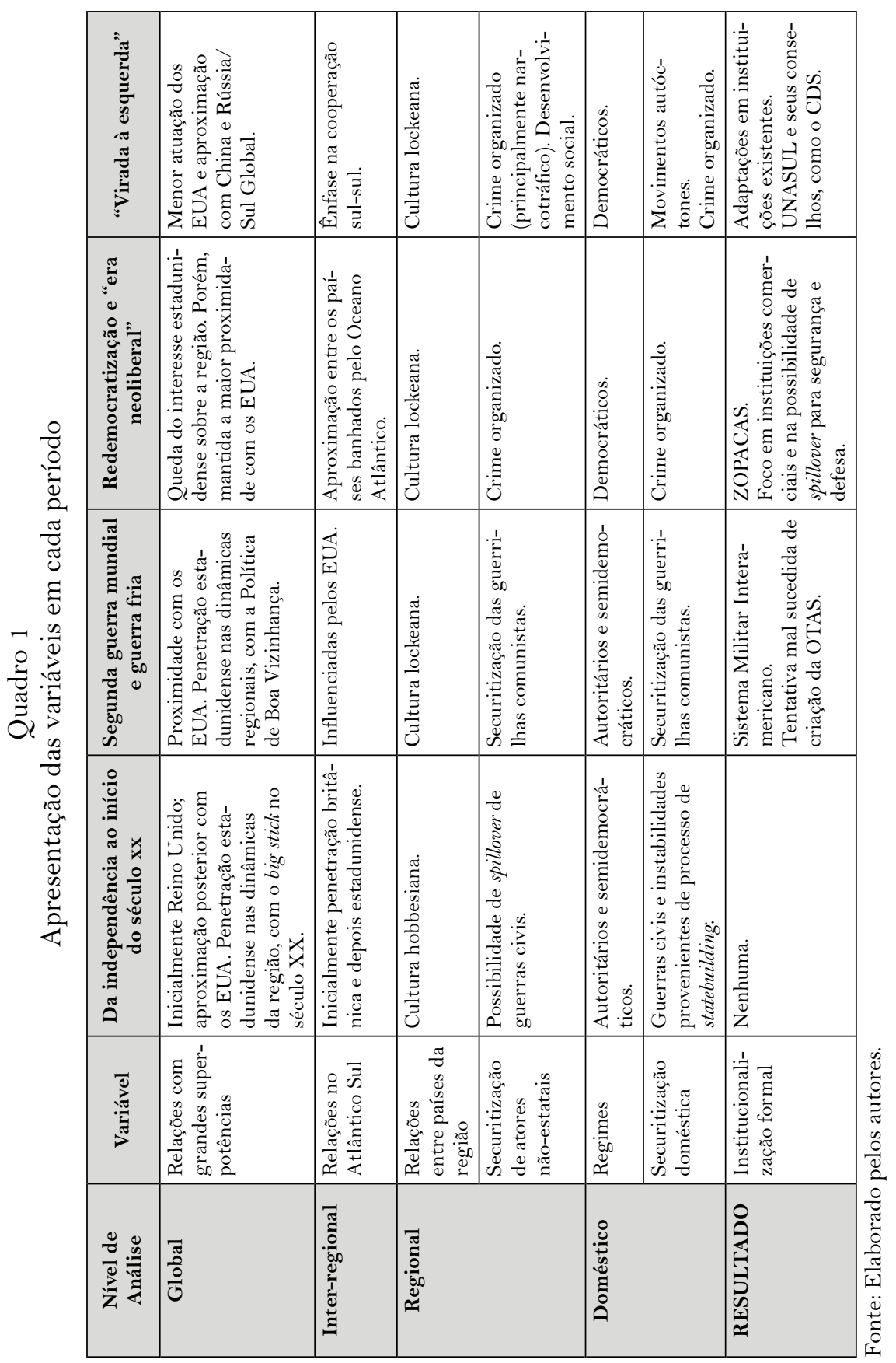




\section{CONCLUSÃO}

Como pudemos observar, é razoavelmente clara a explicação da institucionalização sul-americana em assuntos relacionados à segurança e defesa a partir da ótica dos CRS, aliada ao construtivismo e ao institucionalismo sociológico. A presença de uma cultura lockeana de relações entre os países surgiu como uma condição necessária para essa institucionalização. Além disso, no início, os EUA assumiram papel crucial nesse processo - algo que, ao longo do tempo, foi se tornando cada vez mais desnecessário. O contexto de cada período refletiu-se claramente na institucionalização regional.

Durante o século XIX, as interações conflituosas entre os países da região e a ausência de engajamento estadunidense na construção da cooperação na região resultaram na ausência de mecanismos institucionais ligados à segurança na região. Já durante a Segunda Guerra Mundial e a Guerra Fria, foi desenvolvida uma cultura de coexistência entre os Estados sul-americanos, a despeito de algumas rivalidades. Junto a isso, os EUA passaram a incentivar a cooperação regional em assuntos de segurança (quando fosse de seu interesse) e a ditar a agenda de segurança regional. Nesse sentido, os estadunidenses foram os paymasters da formação do SMI e, de forma indireta, da tentativa de criação da OTAS, que acabaria frustrada.

Com a redemocratização e a tentativa de implementação de modelos neoliberais na região, os Estados Unidos ainda exerciam influência sobre os países sul-americanos, mas engajavam-se cada vez menos nas dinâmicas locais. Com a redução da presença dos mesmos e de outras potências externas, surgiram organizações regionais focadas no comércio, que poderiam vir a construir uma cultura mais pacífica na região, como o Mercosul e a ZOPACAS, no âmbito do Atlântico Sul. Nesse contexto, a América do Sul deveria tornar-se mais segura por meio do aumento da interdependência entre seus países, filosofia que levou à criação, por exemplo, do Mercosul.

Por fim, com a chegada ao poder dos governos de esquerda e centro-esquerda na região, o regionalismo sul-americano passou a focar na integração em áreas como segurança e defesa e na rejeição à hegemonia e influência estadunidenses na região. Somando isso à confiança já previamente construída e a um maior desinteresse dos EUA pela região, viu-se pavimentado o caminho para a construção da UNASUL e do CDS. O foco desses governos nas relações sul-sul levaram, ainda, à tentativa de revitalização da ZOPACAS, que acabou, de fato, estagnada até os dias atuais. Aliás, atualmente, com o aparente fim da "Virada à esquerda" na região, o que já se pode perceber é que essa institucionalização começa a tomar outros rumos, em um contexto em que o último encontro do CDS ocorreu no final de 2016, e que grande parte dos governantes que não são de esquerda na 
região suspenderam sua participação no Conselho. A identidade regional parece alterar-se de novamente, trazendo algumas incertezas sobre o futuro dessa institucionalização.

\section{REFERÊNCIAS}

Abdul-Hak, Ana Patrícia. 2013. O Conselho de Defesa Sul-Americano (CDS): objetivos e interesses do Brasil. Brasília: Fundação Alexandre de Gusmão. 280p.

Amorim, Sérgio Gonçalves de. 2013. "Perspectivas Brasileiras na Convergência entre o SIBIN e a ZOPACAS”. Austral 2 (4): 11-31, jul./dez.

Bernstein, Steven. 2002. "International institutions and the framing of domestic policies: the Kyoto Protocol and Canada's response to climate change". Policy sciences 35: 203-236.

Brasil. 1952.Presidência da República. Decreto $\mathrm{n}^{\circ}$ 30.544, de 14 de fevereiro de 1952. Promulga a Carta da Organização dos Estados Americanos. Diário Oficial da União. Rio de Janeiro.

Buzan, Barry e Ole Waever. 2003. Regions and powers: the structure of international security. Cambridge: Cambridge University Press.

Buzan, Barry, Ole Waever and Jaap de Wilde. 1998. Security: a new framework for analysis. Boulder: Lyenne Rienner.

Caldas, Aderson de Oliveira. 2013. Zopacas e o Brasil:O discurso e as práticas brasileiras na iniciativa de paz e cooperação do Atlântico Sul. 41 f. Artigo (Especialização) - Especialização em Relações Internacionais. Brasília: Universidade de Brasília.

Carvalho, Thales Leonardo. 2018. A "Virada à Esquerda" e as políticas de defesa e políticas externas relacionadas à segurança na América Latina: um estudo comparativo de 16 mandatos presidenciais. 121 p. Dissertação (Mestrado em Ciência Política) Faculdade de Filosofia e Ciências Humanas. Belo Horizonte: Universidade Federal de Minas Gerais.

CEPAL. Comissão Econômica para a América Latina e o Caribe. 1994. El regionalismo abierto en América Latina y el Caribe. La integración económica al servicio de la transformación productiva con equidad, (LC/G.1801-SES.25/4). Santiago, 28 jan.

Finnermore, Martha. 1996. "Norms, culture, and World Politics: insights from sociology’s institutionalism”. International Organization 50 (2): 325-347.

Fuccille, Alexandre. 2014. Conselho de Defesa Sul-Americano (CDS): balanço e perspectivas. In: IX Encontro da Associação Brasileira de Ciência Política Brasília, 4-7 ago. 
Fuccille, Alexandre. 2018. Brasil e o Conselho de Defesa Sul-Americano (CDS): um balanço de uma década de sua existência. In: XI Encontro da Associação Brasileira de Ciência Política. Curitiba, 31 jul.-3 ago.

Fuccille, Alexandre e Lucas Rezende. 2013. Complexo regional de segurança da América do Sul: uma nova perspectiva. Contexto Internacional, 35 (1): 77-104, jan./ jun. http://dx.doi.org/10.1590/So102-85292013000100003.

Fukuyama, Francis. 1992.O fim da história e o último homem. Tradução: Aulyde S. Rodrigues. Rio de Janeiro: Rocco.

Galtung, Johan. 1969. "Violence, peace and peace research". Journal of peace research, 6 (3): 167-191.

Gibbs, Denis Richard. 2011. Mackinder meets Buzan: A Geopolitical Extension to Security Complex Theory with an Emphasis on the Polar Regions. $417 \mathrm{f}$. Tese (Doutorado) - Programme of Political Science, The University of Waikato, New Zealand.

Gratius, Susanne. 2012. The rise of latin american regionalism: the same old thing? IDEAS Foundation, Madri.

Guzzini, Stefano. 2003. "Il construttivismo e il ruolo delle instituzioni nelle relazioni internazionali”. Rassegna italiana di sociologia, 2: 215-236, Apri/Giugno.

Hall, Peter e Rosemary Taylor. 2003. "As três versões do neoinstitucionalismo". Lua nova, 58:193-223. http://dx.doi.org/10.1590/So102-64452003000100010.

Johnston, Alastair. 2001. "Treating international institutions as social environments”. International Studies Quarterly, 45 (4): 487-515, Dec.

JID. Junta Interamericana de Defesa. 2018. Historical overview. Disponível em: <http://www.jid.org/quienes-somos/resena-historica-de-la-sede-de-la-jid>. Acesso em: 12 dez. 2018.

Kacowicz, Arie. 1998. Zones of Peace in the Third World: South America and West Africa in Comparative Perspective. Nova York: State University of New York Press.

Levitsky, Steven; Roberts, Kenneth. 2011. Democracy, development and the left. In: Levitsky, Steven; Roberts, Kenneth (eds.). The ressurgence of Latin American left. Baltimore: The John Hopkins University Press.

Mainwaring, Scott e Aníbal Pérez-Liñán. 2013. Democracy and dictatorships in Latin America: emergence, survival and fall. Cambridge: Cambridge University Press. 
Martins Filho, João Roberto. 1999. "Os Estados Unidos, a Revolução Cubana e a Contra-insurreição”. Revista de Sociologia e Política, 12: 67-82.

Meek, George. 1975. "U.S. influence in the Organization of American States". Journal of Interamerican Studies and World Affairs, 17 (3): 311-325.

Monteiro, Licio Caetano do Rego. 2017. "Geopolítica da Segurança na América do Sul: o papel do Brasil e os dilemas de uma região em transição”. L'espace politique, $1(31)$.

OEA. Organização dos Estados Americanos. Carta da Organização dos Estados Americanos. Disponível em: <http://www.oas.org/dil/port/tratados_A-41_ Carta_da_Organiza\%C3\%A7\%C3\%A3o_dos_Estados_Americanos.htm $>$. Acesso em: 24 abr. 2018.

Paraguassu, Lisandra. 2018. Brasil e outros 5 países suspendem participação na UNASUL. In: Reuters, 20 abr. Disponível em: $<$ https://br.reuters.com/article/topNews/idBRKBN1HR2MH-OBRTP>. Acesso em: 28 abr. 2018.

Penha, Eli Alves. 2011. Relações Brasil-África e geopolítica do Atlântico Sul. Salvador: EDUFBA.

Penha, Eli Alves. 2012. A fronteira oriental brasileira e os desafios da segurança regional no Atlântico Sul. Revista da Escola de Guerra Naval, 18 (1): 113-134.

Penna Filho, Pio. 2003. Regionalismo Segurança e Cooperação : o Atlântico Sul como espaço de possibilidades entre o Cone Sul e a África Austral. Anais eletrônicos... XXVII ANPOCS, Caxambu.

Riggirozzi, Pía. 2012. Regionalism through social policy and policy action: rescaling responsabilities and rights. Economy and Society, 43 (3): 432-454.

Silva, Fabrício Pereira. 2010. Até onde vai a "onda rosa”? Análise de Conjuntura OPSA, n.2.

Silva, Antonio Ruy de Almeida. 2014. O Atlântico Sul na Perspectiva da Segurança e da Defesa. In: NASSER, Reginaldo Mattar; MORAES, Rodrigo Fracalossi. $O$ Brasil e a segurança em seu entorno estratégico. Brasília: IPEA.

Smith, Peter H. 1996. Talons of the Eagle: Dynamics of US-Latin American Relations, New York; Oxford: Oxford University Press.

Souza, Andrea Luiza Fontes Resende de. 2017. As Forças Navais dos Estados Unidos no Atlântico Sul: Um estudo de caso sobre a Quarta Esquadra. 195 f. Dissertação 
(Mestrado) - Programa de Pós Graduação em Relações Internacionais, Pontifícia Universidade Católica de Minas Gerais, Belo Horizonte.

Stewart-Ingersoll, Robert e Derrick Frazier. 2012. Regional Powers and Security Orders: A Theoretical Framework. London: Routledge.

Teixeira, Carlos Gustavo Poggio. 2012. Brazil, The United States, and the South American Subsystem: Regional Politics and the Abscent Empire. Maryland: Lexington Books.

Veiga, Pedro da Motta e Sandra P. Rios. 2007. "O regionalismo pós-liberal na América do Sul: origens, iniciativas e dilemas”. CEPAL Serie Comercio Internacional, 82, Julio.

Wendt, Alexander. 1992. Anarchy is what states make of it: the social construction of power politics. International Organization, 46 (2): 391-425, Spring.

Wendt, Alexander. 1999. Social Theory of International Politics. Cambridge: Cambridge University Press. 


\section{NOTAS}

1. Um dos esforços mais notórios nesse sentido é o de Fuccille e Rezende (2014), ao tentarem apreender lições sobre o papel do Brasil nesse contexto, junto à emergência de um Conselho de Defesa Sul-Americano (CDS).

2. Os níveis de análise foram baseados na obra de Buzan e Waever (2003).

3. Semidemocracias são aqui entendidas a partir dos critérios de Mainwaring e Pérez-Liñán (2013), como países em que há violações parciais de algum (uns) dos princípios elencados: eleição do chefe de governo e da legislatura em eleições competitivas e justas; inclusão da maior parte da população adulta, com um sufrágio quase universal para essas pessoas; proteção dos direitos civis e políticos, como liberdade de imprensa, expressão e organização; e reais condições de governar por parte das autoridades eleitas. Quando há uma violação completa desses princípios, o governo é considerado autoritário.

4. O overlay constitui, basicamente, a interferência de uma grande ou superpotência de modo a alterar ou até mesmo suprimir as dinâmicas locais de segurança, conectando-as às dinâmicas globais. A penetração também caracterizaria tal interferência, mas sem a polarização das dinâmicas locais por parte dessas potências (Buzan e Waever 2003).

5. A paz negativa é entendida aqui como a ausência de conflitos em um contexto em que as controvérsias entre os atores do sistema ainda não foram resolvidas, com grandes possibilidades de ocorrência de um novo conflito (Galtung 1969).

6. Os EUA continuaram a monitorar a região através, por exemplo, do Comando Militar do Sul (Monteiro 2017).

7. A Quarta Esquadra do Atlântico Sul dos Estados Unidos foi criada em 1943 e desativada em 1950, sendo reativada em 2008 (Souza 2017). 


\section{A INSTITUCIONALIZAÇÃO NO COMPLEXO REGIONAL \\ DE SEGURANÇA SUL-AMERICANO: UMA COMPARAÇÃO ENTRE QUATRO PERÍODOS HISTÓRICOS}

\section{RESUMO}

O artigo pretende apresentar evidências sobre a consolidação das identidades e interações relacionadas à segurança entre os atores sul-americanos na forma de instituições regionais. Recorremos à comparação das dinâmicas regionais em diferentes períodos, em quatro diferentes níveis de análise, visando a entender como as mesmas interferiram nessa institucionalização.

Palavras-Chave: Complexos Regionais de Segurança; Instituições; América do Sul; Atlântico Sul.

\section{ABSTRACT}

The article aims to show evidence of the consolidation of identities and interactions related to security among South American actors through regional institutions. We compare regional dynamics in different periods, using four levels of analysis, intending to understand how they affect this institutionalization.

Keywords: Regional Security Complexes; Institutions; South America; South Atlantic. 